\title{
A ABORDAGEM CTSA SOB A PERSPECTIVA DOS TEMAS GERADORES EM FREIRE PARA FORMAÇÃO CONTINUADA DE PROFESSORES DE CIÊNCIAS: UM CAMPO DE CONFLITOS SIMBÓLICOS NA REGIÃO DE ANGRA DOS REIS
}

\author{
Renata Monteiro ${ }^{1}$, Guaracira Gouvêa ${ }^{2}$ e Celso Sánchez ${ }^{3}$ \\ ${ }^{1}$ Universidade do Estado do Rio de Janeiro (UNIRIO)/Programa de Pós-Graduação em \\ Educação/Bolsista de mestrado CAPES/Observatório da Educação/renatas_monteiro@hotmail.com \\ 2UNIRIO/Programa de Pós-Graduação em Educação/guaracirag@uol.com.br, \\ ${ }_{3}^{3}$ NIRIO/Departamento de didática/celso.sanchez@hotmail.com
}

\begin{abstract}
Resumo
Neste trabalho buscamos apresentar os primeiros resultados do projeto "Ensino de Ciências: desempenho de estudantes, práticas educativas e materiais de ensino" inserido no Programa Observatório da Educação/CAPES. O projeto tem como objetivo analisar como a relação CTSA se reflete na prática docente do ensino de ciências, no material didático e nas questões do ENEM que versam sobre Energia, numa região caracterizada pelo contexto da produção energética de matriz nuclear. A fim de atender esta demanda, tendo em vista um campo de conflitos simbólicos e a dimensão ontológica, foi adotada a metodologia CTSA sob a perspectiva dos Temas Geradores em Freire. Nesta oportunidade serão apresentados os resultados da primeira e segunda etapa da metodologia adotada que inclui o levantamento e análise de dados preliminares da região, a partir dos quais foram pensadas ações para abordagem de um curso de formação continuada ofertado a professores de ciências dos municípios de Angra dos Reis, Paraty e Mangaratiba.
\end{abstract}

Palavras Chaves: Energia, CTSA, Temas Geradores, formação continuada de professores de ciências.

\begin{abstract}
In this work we try to present the first results of the project "Education of Sciences: performance of students, educational practices and teaching materials" inserted in the Programa Observatório da Educação/CAPES. The project has the objective to analyze how the Science, Technology, Society and Environment (STSE) approach reflects in the teaching practices of the education of sciences, in the didactic materials and in the questions of the ENEM that addresses Energy, in a region characterized by the context of the nuclear energy production. In order to take care of this demand, having in view a field of symbolic conflicts and the ontological dimension, was adopted the STSE methodology under the perspective of the Generating Subjects in Freire. In this opportunity will be presented the results of the first and the second stages of the adopted methodology that includes the survey and analysis of preliminary data of the region, from which actions for boarding a course of continued formation had been outlined to offer to the science teachers from the cities Angra dos Reis, Paraty and Mangaratiba.
\end{abstract}

Keys words: Energy, STSE, Generating Subjects, continued formation of science teachers. 
Este trabalho apresenta os primeiros resultados do projeto Ensino de Ciências: desempenho de estudantes, práticas educativas e materiais de ensino, parceria entre Universidade Federal do Estado do Rio de Janeiro/UNIRIO, a Universidade Federal do Rio de Janeiro/UFRJ, Universidade de São Paulo/USP e conta com o apoio do Edital 01/2008/CAPES/INEP/SECAD do Programa Observatório da Educação.

Nesta oportunidade consideramos a escola como o lócus privilegiado da disseminação de saberes historicamente e socialmente legitimados e um possível espaço para a construção de pensamento crítico e do exercício de práticas sociais em busca de cidadania emancipadora por meio de práticas visando a articular informações oriundas de diferentes experiências sociais. As pesquisas em educação, bem como políticas públicas têm manifestado, por meio de publicações e de ações, preocupações acerca da necessidade de que alunos têm de se comunicarem, problematizarem e argumentarem ao se depararem com problemas de sua vida cotidiana, para que os resolvam criticamente, para nós em uma perspectiva que considere todo o patrimônio da humanidade (tangível ou intangível; material ou imaterial). Da mesma forma, consideramos que deva ser abordada a formação inicial e continuada de professores.

No sentido, de atendermos a esta demanda, decidimos escolher um tema que fosse possível de ser apresentado em diferentes contextos discursivos e problematizá-lo. Em nosso caso nos discursos das questões do Exame Nacional do Ensino Médio ENEM; das práticas de ensino de professores de ciências, dos livros didáticos de ciências do ensino médio e ainda fosse um tema estruturante do ensino de ciências, tanto do ponto de vista da história da ciência como de suas relações sociais, culturais, tecnológicas e ambientais. Estas relações têm sido conceituadas pela comunidade de educadores em ciências no âmbito da abordagem Ciência - Tecnologia - Sociedade Ambiente (CTSA) para o ensino de ciências.

Assim, o tema escolhido foi ENERGIA, e, nossa questão de investigação diz respeito a como, em diversas instâncias educacionais, está sendo abordado o tema das relações sociais, culturais, tecnológicas e ambientais da energia no mundo contemporâneo.

Para buscarmos possíveis respostas a essa questão, traçamos os seguintes objetivos: analisar em que medida as demandas (i) pela contextualização de conceitos científicos em termos de suas relações sociais, tecnológicas e ambientais e (ii) pelo desenvolvimento de possibilidades de leitura, interpretação, argumentação e atitudes frente a questões sócio-científicas, estão postas pelos Exames Nacionais do Ensino 
Médio, e materializadas em materiais didáticos; analisar práticas de uso em sala de aula, desses diferentes tipos de material didático voltados para abordagem de conceitos científicos na perspectiva de suas relações sociais tecnológicas e ambientais.

Como cenário para desenvolvermos a investigação, cada universidade escolheu um município no qual a população estivesse envolvida com alguma forma de produção de energia em seus aspectos sociais e ambientais. Assim, a UNIRIO e a UFRJ escolheram, respectivamente, Angra dos Reis e Macaé, cidades situadas no Estado do Rio de Janeiro e a USP selecionou São Paulo e Sorocaba, situadas no Estado de São Paulo. Neste trabalho, estaremos apresentando os primeiros resultados de nossa investigação desenvolvida pela UNIRIO em Angra dos Reis e que estão associados ao objetivo de analisar as práticas de professores.

A perspectiva colocada é que não iríamos apenas observar e sim participar da prática dos professores e adotamos a perspectiva de Formação Continuada como parte da Educação Continuada dos professores em seu cotidiano de prática docente, no sentido de ressignificarem o seu fazer. Neste sentido adotamos a reflexão das relações ciência, tecnologia, sociedade e ambiente (CTSA) sob a perspectiva dos temas geradores em Freire, conforme exposto a seguir.

\section{CTSA: alguns pressupostos teóricos}

A concepção linear da ciência e tecnologia como um processo fechado e destituído de inferências humanas apresenta uma limitação interpretativa das relações entre ciência, tecnologia e sociedade. O contexto do pós-guerra legou aos Estados, especialistas e técnicos a responsabilidade pelas inovações tecnológicas que atendessem a demanda militar, símbolo não apenas do domínio no campo, mas de um saber-poder na concepção foucaultiana. Para Cerezo este período se norteou pela idéia de que o acúmulo do conhecimento científico e tecnológico produzisse, de maneira linear, desdobramentos como progresso econômico e bem estar social, o que o autor ilustra da seguinte forma: “+ ciência $=+$ tecnologia $=+$ riqueza $=+$ bem estar social” $(1998$, p.2)

Herrera (2003) analisa o processo de construção de uma racionalidade "mecanicista linear" na gestão da ciência e tecnologia ocidental. Neste aspecto é entendida como um modelo universal, a que considere a ciência e tecnologia (C\&T) como autônomas, regidas por forças endógenas e externas a condição humana, um "processo fechado e neutro". (Herrera, 2003, p.29). Esta condição contribui a concepção 
de que os países latino-americanos devem se adiantar ao receituário da "sociedade moderna", o que leva a considerá-los num estágio de desenvolvimento aquém, devendo cumprir a mesma trajetória e política científica e tecnológica dos países centrais. Deste viés torna-se quase que lugar comum nas críticas ao fluxo global de C\&T que partindo dos países europeus, nas décadas de 1960 e 1970, desconsiderou as diferentes características culturais e necessidades sociais dos países periféricos, entendidas como obstáculos ao desenvolvimento. Segundo Herrera (2003) este processo de transferência passiva de C\&T teria contribuído a perda de autonomia, aumento vulnerabilidade e dependência externa, tendo sido auxiliado por instituições e centros de pesquisas internacionais. O autor acredita, entretanto, que a perspectiva que incorporação científica e tecnológica advinda de fontes exógenas aos países periféricos pode ser producente na medida em que esteja em conformidade com o contexto local e se estabeleça por meio de processos coletivos de escolhas conscientes, conforme coloca (Herrera, 2003, p.43):

\footnotetext{
Entretanto, quando o desenvolvimento é concebido como uma transformação endógena, na qual a experiência externa não é imposta, mas voluntariamente incorporada, as características culturais específicas dos países subdesenvolvidos podem ser, ao invés de obstáculos, um núcleo dinâmico do processo de mudança.
}

Os movimentos contracultura e ambientalistas, da década de 1960 e 1970, pleitearam maior participação pública nos processos políticos sendo dirigidas críticas ao ensejo tecnocrático das decisões. Esta mudança pode ser entendida como um processo em que o otimismo científico e tecnológico sede lugar a inquietação e dúvida quanto aos riscos e os perigos da C\&T. Para Cerezo (1998) teriam surgido focos de reavaliação das relações CTSA partindo dos países centrais, caracterizadas em duas vertentes. Uma, com interesse na dimensão da C\&T do ponto de vista de seus antecedentes sociais (tradição européia), e outra, com ênfase nas conseqüências da ciência e tecnologia na sociedade (tradição EUA). Ambas teriam em comum o intuito de contextualizar a ciência e tecnologia como um "produto imanentemente social, em que os elementos não técnicos, como valores morais, convicções religiosas, interesses profissionais e pressões econômicas desempenham um papel decisivo em sua gênese e consolidação" (1998, p.2). Nesta perspectiva o movimento CTSA objetiva consubstanciar uma visão menos ingênua quanto ao desenvolvimento científico e tecnológico o que se reflete na organização curricular das disciplinas de ciências do ensino médio. 
De acordo com a Lei de Diretrizes e Bases da Educação Nacional (LDB) o ensino médio é entendido como parte integrante da educação básica sendo fundamental para formação do indivíduo enquanto cidadão, devendo "permitir a percepção da interação da ciência e da tecnologia com todas as dimensões da sociedade, considerando as suas relações recíprocas, oferecendo ao educando oportunidade para que ele adquira uma concepção ampla e humanista da tecnologia" (Bazzo, Pinheiro e Mattos, 2007, p.2). Estes autores destacam ainda, a função professoral enquanto articuladora dos conhecimentos científicos para resolução de "situações-problema" do cotidiano dos alunos a fim de superar a fragmentação disciplinar e o enfoque quantitativo.

Aikenhead (apud Santos e Mortimer p.106) aponta a influência dos meios de comunicação de massa na construção de valores e crenças dos estudantes, a que considera de abordagens desvinculadas do contexto social, em que reside a idéia de neutralidade e linearidade da C\&T. Nesta perspectiva, Angotti e Auth (2001) colocam algumas questões a cerca da C\&T nas "implicações sociais e o papel da educação". Embora haja vista que os avanços da ciência e tecnologia não se processam de forma equânime, e que o modelo de produção e consumo hegemônico aceleram a degradação ambiental e as desigualdades sociais, o que esperar da educação em ciências num país como o Brasil diante da falta de recursos e de um sistema educacional articulado? Como proporcionar uma formação no ensino de ciências que possibilite a tomada de decisões informadas e a participação nas políticas públicas de C\&T ao revés do monopólio tecnocrático?

A problematização deste quadro se acentua quando Auler e Bazzo (2001) discutem as limitações e os desafios para implementação do movimento CTS no contexto educacional brasileiro, diante de nossa inexperiência democrática e submissão científico-acadêmica ao eixo de produção hegemônica. Apontam o fato do movimento CTS ter surgido em países que tiveram seu crescimento pautado no modelo de desenvolvimento a que pretendemos alcançar e que seria imanente ao imaginário de muitos brasileiros aspirar ao modelo de produção e consumo destes países. Desta forma, indagam qual tipo de racionalidade os professores de ciência estariam reproduzindo e quais suas percepções sobre as implicações CTSA no desenvolvimento de suas práticas de ensino-aprendizagem. Esta preocupação pode ser elucidada no seguinte trecho (Auler e Bazzo, 2001, p.3):

Considerando o discurso dos meios de comunicação e de outros segmentos 
formadores de opinião, não seria meta prioritária de parcela significativa da população a busca do "primeiro mundo"? Não estaríamos querendo fazer uso das mesmas estratégias em termos de política econômica e tecnológica, esquecendo/ignorando suas conseqüências em termos ambientais, culturais e sociais?

Alguns autores destacam a necessidade de contextualizar os aspectos históricos e epistemológicos da C\&T nas práticas docentes do ensino de ciências. Esta perspectiva é colocada por Angotti e Auth que atentam para importância da formação continuada de professores do ensino fundamental e médio, assim como de práticas cooperativas que os envolvam e os desafiem, tal como discorrem (2001, p.23):

\begin{abstract}
Mas, como em nosso país este tipo de formação está longe de ser uma realidade, de maneira sistemática, o desafio está em, inicialmente, conseguir envolver os professores em atividades que enfocam essas questões para, paulatinamente, comprometê-los. O desafio é envolver/comprometer os professores em atividades colaborativas, para inquietá-los e desafiá-los em suas concepções de ciência, de "ser professor" e em suas limitações nos conteúdos e nas metodologias.
\end{abstract}

A "matriz teórico-filosófica" CTSA com a perspectiva educativa de Paulo Freire tem sido estudada desde 1970. A tese de doutorado de Auler e desdobramentos, como a contribuição de artigos recentes ao periódico "Alexandria Revista de Educação em Ciência e Tecnologia", apontam-se a validade desta correlação diante da possibilidade de se promoverem práticas de ensino-aprendizagem contextualizadas com os aspectos locais e com a dimensão ontológica. O potencial da abordagem temática - temas geradores - de Freire, não se mede apenas pela superação disciplinar, mas ainda, e, sobretudo pelo potencial participativo e de leitura crítica do mundo e das relações CTSA.

A fim de propor uma ação de formação continuada para professores de ciências que fosse além da qualificação para as necessidades de formação para o trabalho, colocados pela sociedade contemporânea, mas que possibilitasse um diálogo decodificador do embates estabelecidos na estrutura social e na dinâmica escolar, optamos pela matriz filosófica de abordagem CTSA e perspectiva dos temas geradores em Freire.

\title{
Abordagem CTSA e a perspectiva dos temas geradores de Freire
}

Diante dos pressupostos teóricos expostos e das considerações polissêmicas e polifônicas do tema ENERGIA, a que propomos investigar, aproximamos a investigação do referencial metodológico de abordagem CTSA sob a perspectiva 
freiriana, inspirada nos autores Auler, Dalmolin e Fenalti (2009) divididas em cinco etapas.

Na primeira etapa se realizou a caracterização de um levantamento preliminar das condições da localidade e entrevistas informais realizadas nas escolas e na coordenadoria de educação. A segunda etapa se desenvolveu diante da análise dos dados obtidos, em que emergem algumas questões relacionadas aos conflitos e contradições CTSA na localidade e no contexto de produção energética. A terceira etapa, "diálogos descodificadores", se realizará no primeiro momento do curso de formação continuada para professores de ciências em que se observe a perspectiva CTSA em seus discursos, com identificação dos temas geradores do debate. A quarta etapa consiste na produção do material didático atrelado aos temas geradores, postos anteriormente. Na quinta etapa se procederá o segundo momento do curso por meio de uma abordagem didática que contemple as questões e embates inerentes a relações CTSA no contexto escolar da uma região marcadamente influenciada pela produção energética nuclear.

A seguir serão expostos os resultados da primeira etapa e segunda etapa da metodologia adotada permitindo elencar algumas questões preliminares a partir da análise do discurso. Estes processos pretendem subsídios para o planejamento das etapas posteriores, em que se insere a oferta de um curso de formação continuada a partir de um enfoque local/regional.

\section{Angra dos Reis: do município à região}

A cidade de Angra dos Reis se localiza na microrregião Costa Verde, inserida na região Sul Fluminense do Estado do Rio de Janeiro. Embora a pesquisa tenha a priori focada suas ações no município de Angra dos Reis, se considerou a necessidade de ampliar esta abordagem que inicialmente partiu da divisão política, entendida como um conceito de região geográfica. A perspectiva sócio-cultural apontou a premissa de serem abrangidos na pesquisa os municípios circundantes, Paraty e Mangaratiba. A primeira consideração deste fato advém da estrutura formal do ensino médio que abrange os três municípios - Angra dos Reis, Paraty e Mangaratiba, e que tem como pólo administrativo e diretrizes de ensino o mesmo órgão, a Coordenadoria Estadual da Baía de Ilha Grande. Esta coordenadoria se localizada no município de Angra dos Reis e é responsável por 18 unidades escolares, sendo três localizadas no município de Paraty, 
outras duas no município de Mangaratiba, e as demais no município de Angra dos Reis, nesta se inclui uma escola indígena.

Segundo dados do IBGE (2009), as principais atividades econômicas da região são os terminais marítimos, o cultivo da banana no setor agrícola, a pesca como atividade tradicional, atividades de lazer marítimo, veraneio e turismo. A Eletronuclear localizada em Angra dos Reis pode ser considerada uma referência científica e tecnológica na região com desdobramentos na economia local, o que se deve ao contexto de produção energética com origem nas centrais nucleares. Atualmente as usinas de Angra 1 e Angra 2 estão em operação, enquanto Angra 3 está fase de construção. Cabe compreender no espoco geral do projeto como os impactos da produção energética das centrais nucleares se refletem na prática docente dos professores de ciências, nos materiais didáticos utilizados e nas questões de energia do ENEM, tendo como referencial teórico a abordagem CTSA e temas geradores em Freire.

\section{Análise dos dados}

Os dados da pesquisa advém de inserção da equipe no local/região por meio de quatro viagens. O primeiro estudo ocorreu dois meses após a notícia de um vazamento de radiação na Usina Nuclear Angra 2 em julho de 2009, o segundo em novembro do mesmo ano, o terceiro e quarto estudos em janeiro e março de 2010, após os episódios de soterramento com vítimas.

O quadro de sujeitos da pesquisa é formado pelos representantes da coordenadoria supracitada, diretoras e professores das escolas de ensino médio da região, em particular os professores de ciências das disciplinas de física, química e biologia. A análise dos dados se baseou na análise do discurso destes atores sociais, entendida como construção social da linguagem capaz de possibilitar abordagens que caráter ontológico em que se observem ideologias, valores e crenças. Desta forma foram identificados campos de conflitos simbólicos que forneceram condições para distinguir as escolas em três grupos.

As 18 unidades escolares de ensino médio da região foram agrupadas de acordo com a relação que estabelecem com a usina nuclear. $\mathrm{O}$ primeiro grupo é composto por escolas localizadas nas vilas residenciais da usina nuclear, denotando uma estreita vinculação a que se considere a obtenção de recursos financeiros da mesma, que se aplicam, por exemplo, na contratação de professores. O segundo grupo é formado por 
escolas fora das vilas, algumas se localizam em bairros próximos a usina nuclear e outras em bairros distantes, englobando as escolas dos municípios circundantes. Este grupo se caracteriza pela ausência do recebimento dos recursos supracitados. O terceiro grupo é formado por uma escola indígena - bilíngüe, que se localiza na Aldeia Guarani Sapukai, no município de Angra dos Reis, e que tem características culturais próprias do grupo étnico guarani.

O primeiro grupo obteve o melhor índice de aprovação da região no ENEM em 2009. Embora este grupo receba recursos financeiros da usina nuclear suas unidades escolares são regidas pelas normas da Secretaria de Educação do Estado do Rio de Janeiro, tal como as demais. Nas entrevistas se colocou o fato de cerca de $80 \%$ dos alunos advirem da população localizada no entorno das vilas residenciais, sendo diminuta a demanda escolar dos filhos de funcionários da usina que "saem para estudar fora" visto o elevado potencial aquisitivo. No discurso da direção foi possível identificar a preocupação com as notícias veiculadas pela mídia sobre a contaminação de funcionários com material radioativo. Segundo colocado não teria acontecido nada grave, existindo recursos para prevenção e tomada de atitude caso haja algum acidente. Este ponto de vista toma outra dimensão a partir da fala de atores de unidades escolares desvinculadas a usina nuclear, sendo possível identificar alguns conflitos discursivos.

As unidades escolares que se localizam no entorno da usina nuclear não recebem nenhum tipo de recurso da mesma, "não recebe nem uma folha, nem uma caneta", embora estejam em sua área de evacuação/risco. Nas falas se colocam preocupações com a construção de Angra III, uma vez que ao entrar em funcionamento a demanda de alunos aumentará. Em relação ao acidente radioativo, ao revés do exposto pelo grupo anterior, se expõe que a notícia foi abafada saindo na mídia semanas após a contaminação e que "o negócio foi feio" tendo "atingindo partes internas dos trabalhadores". Cabe ressaltar desta passagem o potencial dos veículos de divulgação científica enquanto instrumentos de reflexão das relações CTSA. Segundo Bazzo e Marcelo (2006) a divulgação científica através dos meios de comunicação pode contribuir a dimensão educativa como ferramenta para criação de um público crítico sobre os impactos sociais da C\&T, em que se incluam os riscos a saúde humana e ao meio ambiente.

O terceiro grupo é formado pela escola indígena pertencente ao grupo étnico guarani. Ao perguntarmos sobre uma cartilha indígena observada na coordenadoria de educação da região, uma das falas atrelou a escola indígena à condição dos que sempre 
aceitam os projetos propostos, numa perspectiva de valorização de seu aspecto colaborativo, o que pode ser inferido numa outra dimensão como crédito ao caráter dócil e mesmo passivo da cultura indígena. Entretanto, em outra fala, também de diretoria, foi enfatizada a dificuldade de se trabalhar com os professores indígenas.

Acerca dos projetos realizados pelas escolas foi possível diagnosticar um relativo grau de autonomia. A maioria tratava da questão ambiental, ditos projeto de Educação Ambiental (EA). Percebeu-se nas falas, todavia, a personificações de projetos atrelados a determinado professor, sem a participação do coletivo escolar. Diante da complexidade da temática socioambiental de perspectiva CTSA, numa análise mais apurada, seria possível considerar a existência de abordagens reducionistas nos projetos apresentados, limitados a órbita da reciclagem e do artesanato.

A partir da análise dos dados identificamos nos discursos dos sujeitos entrevistados surgem alguns conflitos e contradições a partir de quem fala e de onde fala. Além dos aspectos vinculados ao sistema formal de ensino existem na região comunidades caiçaras, indígenas e quilombolas com participação nos respectivos movimentos sociais brasileiros. A construção teórica apresentada ilustra formas diferenciadas de pensar as relações CTSA e nos interessa perceber como isso está presente na prática docente de ciências, no livro didático e nas questões de energia do ENEM. Desta forma, o curso de Educação Continuada destinado aos professores das disciplinas de física, química e biologia tem como objetivo ampliar o campo de conflito de seus discursos para posterior análise e intervenção didática, criando ainda, condições de participação dos professores na pesquisa.

\section{Da análise dos dados ao curso de formação continuada}

A referência metodológica adotada permitiu o desenvolvimento de atividades consecutivas e complementares que colocasse em evidencia questões pertinentes ao contexto CTSA nas unidades escolares dos municípios de Angra dos Reis, Paraty e Mangaratiba. Nossa proposta, de inspiração freiriana, se baseou nas etapas descritas por Auler, Dalmolin \& Fenalti (2009). Na primeira etapa se realizou um levantamento preliminar da localidade por meio de conversas informais nos espaços pertinentes aos atores sociais envolvidos no ensino médio. Na segunda etapa foram realizadas análises dos dados auferidos em que se optou por abranger a pesquisa aos municípios 
fronteiriços identificando ainda a configuração de um campo de conflitos simbólicos. A etapa seguinte engloba a o curso de formação continuada a que se propõem "diálogos decodificadores" entre os participantes e a equipe do projeto a fim de criar condições em que emergem os temas geradores dos embates CTSA, refletidos na visão do professor de ciências. A quarta etapa consiste na "redução temática" em que se elabore uma apresentação didática que incorpore os temas alavancados na etapa anterior com abordagem de uma equipe interdisciplinar. $\mathrm{Na}$ quinta etapa se processa o desenvolvimento didático de conceitos unificadores das disciplinas, tal como o conceito de energia, tendo como referência os temas geradores, com dinâmicas de grupo e a proposição de um plano de aula. Deste curso serão selecionados quatro professores que tenham interesse em se integrar a pesquisa para que se proceda à investigação de suas práticas de ensino-aprendizagem e a utilização de material didático no ensino de ciências. Entre os critérios de alocação das vagas se pretende contemplar os três grupos escolares referendados, visto os conflitos e as condições estruturalmente diferentes em que se inserem.

\section{Referências Bibliográficas}

ANGOTTI, João A.P.; AUTH, Milton A. Ciência e Tecnologia: implicações sociais e o papel da educação. Revista Ciência \& Educação, v.7, n.1, p. 15-27, 2001.

AULER, Décio; BAZZO, Walter A. Reflexões para a implementação do movimento CTS no contexto educacional brasileiro. Revista Ciência \& Educação, v.7, n.1, p. 1-13, 2001.

AULER, Décio A.; FENALTI, Veridiana; DALMOLIN, Antônio M.T. Abordagem temática: natureza dos temas em Freire e no enfoque CTS. Alexandria Revista de Educação em Ciência e Tecnologia, v2, n1, p.67-84, mar.2009

CEREZO, Antonio L. Ciência, Tecnologia y Sociedad: el estado de la cuestión en Europa y Estados Unidos. Revista Iberoamericana de Educación, n.18, pp. 41-68, 1998.

HERRERA, Almicar. Novo enfoque do desenvolvimento e o papel da ciência e tecnologia. In Renato Dagnino; Hernán Thomas (org.). Ciência, Tecnologia $e$ Sociedade: uma reflexão latino-americana (pp. 25-45). Taubaté, SP. Cabral Editora e Livraria Universitária, 2003.

IBGE (2009). http://www.ibge.gov.br/cidadesat/topwindow.htm? Acesso em 14 de fevereiro de 2009.

MARCELO, Valério; BAZZO Walter A. O papel da divulgação científica em nossa sociedade de risco: em prol de uma nova ordem de relações entre ciência, tecnologia e sociedade. Revista Iberoamericana de Educación, n.7, setempo-dezembro, 2006. 
PINHEIRO, Nilcéia A.M.; MATOS, Eloíza A.S.A.; BAZZO, Walter A. Refletindo acerca da ciência, tecnologia e sociedade: enfocando o ensino médio. Revista Iberoamericana de Educación, n.44, maio-agosto, 2007.

SANTOS, Wildson L. P.; MORTIMER, Eduardo F. Tomada de decisão para ação social responsável no ensino de ciências. Ciência \& Educação, v.7, n.1, p.95-111, 2001. 